\section{Pacific Northwest}

National Laboratory

Operated by Battelle for the

U.S. Department of Energy

\title{
Energy Code Compliance in a Detailed Commercial Building Sample: The Effects of Missing Data
}

\author{
R. Biyani \\ E. Richman
}

September 2003

Prepared for the U.S. Department of Energy under Contract DE-AC06-76RL01830 


\title{
Energy Code Compliance in a Detailed Commercial Building Sample: The Effects of Missing Data
}

\author{
R. Biyani \\ E. Richman
}

September 2003

Prepared for

the U.S. Department of Energy

under Contract DE-AC06-76RL01830

Pacific Northwest National Laboratory

Richland, Washington 99352 


\section{Summary}

Most commercial buildings in the U.S. are required by State or local jurisdiction to meet energy standards. The enforcement of these standards is not well known and building practice without them on a national scale is also little understood. To provide an understanding of these issues, a database has been developed at PNNL that includes detailed energy related building characteristics of 162 commercial buildings from across the country. For this analysis, the COMcheck ${ }^{\mathrm{TM}}$ compliance software (developed at PNNL) was used to assess compliance with energy codes among these buildings. Data from the database for each building provided the program input with percentage energy compliance to the ASHRAE/IESNA Standard 90.1-1999 energy as the output. During the data input process it was discovered that some essential data for showing compliance of the building envelope was missed and defaults had to be developed to provide complete compliance information. This need for defaults for some data inputs raised the question of what the effect on documenting compliance could be due to missing data. To help answer this question a data collection effort was completed to assess potential differences. Using the program Dodge View, as much of the missing envelope data as possible was collected from the building plans and the database input was again run through COMcheck ${ }^{\mathrm{TM}}$. The outputs of both compliance runs were compared to see if the missing data would have adversely affected the results. Both of these results provided a percentage compliance of each building in the envelope and lighting categories, showing by how large a percentage each building either met or fell short of the ASHRAE/IESNA Standard 90.1-1999 energy code. The results of the compliance runs showed that $57.7 \%$ of the buildings met or exceeded envelope requirements with defaults and that $68 \%$ met or exceeded envelope requirements with the actual data. Also, $53.6 \%$ of the buildings met or surpassed the lighting requirements in both cases. The dataset of 162 buildings is not large enough to accurately apply theses findings to all commercial buildings across the U.S., but it does provide a rough idea of what to generally expect. This database also has other uses such as characterization of commercial buildings by each specific data point and in splitting up the total of 162 buildings into smaller subsets to characterize such groups as large (>5000 sq $\mathrm{ft})$ or small $(<5000 \mathrm{sq} \mathrm{ft})$ commercial buildings. 


\section{Table of Contents}

Summary ...................................................................................................... iii

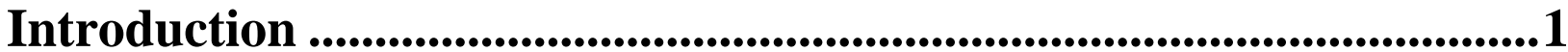

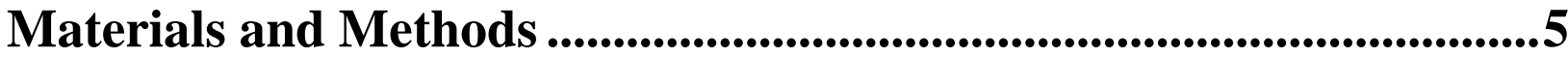

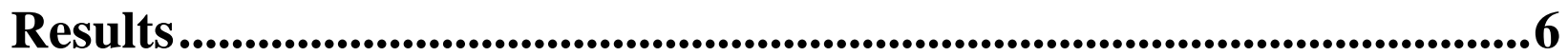

Discussion and Conclusion ................................................................

Acknowledgements ..............................................................................................10

References .....................................................................................................11 


\section{Figures}

Figure 1. Commercial Building Characterization: Exterior Wall Type for Large Buildings..................... 1

Figure 2. Distribution of Difference in Compliance between Defaults and Complete Data........................ 6

Figure 3. Change as a Result of Complete Data .............................................................................. 7

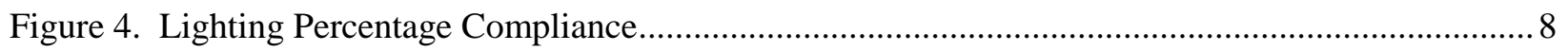

\section{Tables}

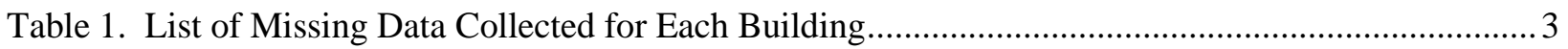

Table 2. Data Previously Collected for Each Building ..................................................................... 4 


\section{Introduction}

In 1995, there were 4.6 million commercial buildings in the United States that consumed over 5.3 quadrillion Btu of energy at a cost of about 70 billion dollars (Swenson 1998). Today's commercial building energy costs per year are the same or higher as a result of the construction of additional buildings. Most states in the United States have an energy code that commercial buildings must meet. Some states use the codes already set forth by International Code Council or American Society of Refrigerating and Air-Conditioning Engineers Inc. (ASHRAE) and some create their own. Because of the lack of data on the enforcement of these codes or even lack of having a code, it is not known whether commercial buildings actually meet them. To better understand actual compliance, a detailed commercial building characteristics dataset of 162 buildings developed at PNNL was used as a national data source of new construction trends.

This database was constructed from information on building characteristics related to energy loss and efficiency of commercial buildings. A goal of the dataset was to be able to present information on building trends to answer questions related to current practice that effected energy efficiency programs, code adoption, and energy use. One example of this is the distribution of exterior wall type for commercial buildings across the country shown in Figure 1. This information shows how frequently each wall type occurs among the 143 buildings that are labeled as 'large buildings' (>5000 sq ft summed area) indicating that masonry and steel framed exterior walls were the most common.

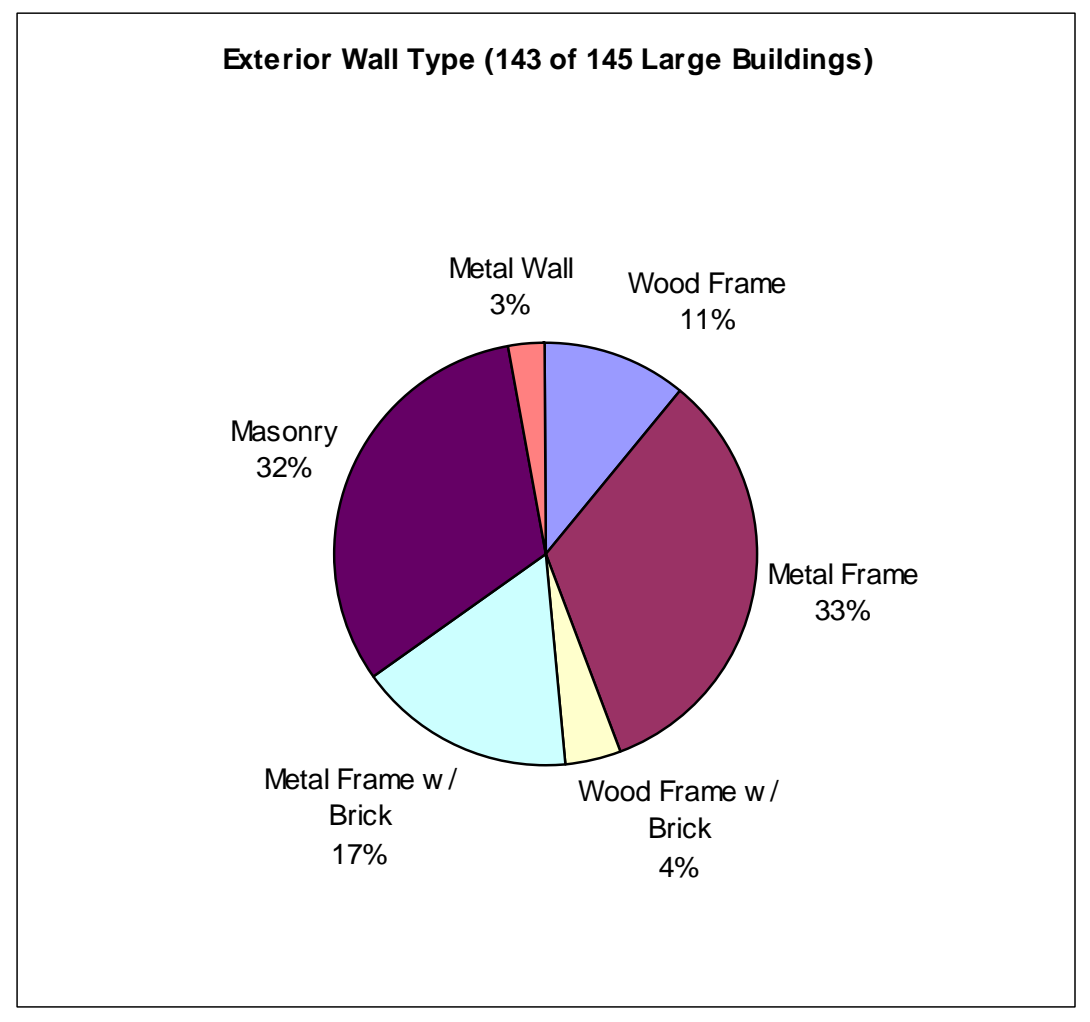

Figure 1. Commercial Building Characterization: Exterior Wall Type for Large Buildings 
One project that made use of the data was an assessment of how these buildings were complying with applicable energy codes. The data from the dataset was used as input to COMcheck ${ }^{\mathrm{TM}}$ (U.S. DOE 2003), an energy compliance software tool. The results of this would then provide a percentage compliance with ASHRAE/IESNA Standard 90.1-1999 (ANSI/ASHRAE/IESNA 1999). The COMcheck ${ }^{\mathrm{TM}}$ tool calculates prescriptive compliance with lighting, mechanical equipment, and envelope. The envelope term refers to the shell of the building (walls, roof, floor) and how well insulated it is from outside weather conditions. Some of the data that $\mathrm{COM}$ check $^{\mathrm{TM}}$ required for envelope compliance calculation was not collected in the development of the dataset so defaults for each missing item had to be created. The data with defaults for the missing information was run through COMcheck ${ }^{\mathrm{TM}}$ and percentage compliance readings obtained.

However, without the assurance of complete and accurate data, the results could be considered inaccurate. It was also desirable to know if additional data collection for future similar analysis would have any meaningful effect on the results.

The work focused on gathering the missing data for each of the 162 commercial building plans so that a more accurate percentage compliance reading might be determined by COMcheck ${ }^{\mathrm{TM}}$ (U.S. DOE 2003). This would also show how much the missing data might affect the results and the accuracy of the defaults that were used. Because the missing data only affected the envelope part of the percentage compliance reading, only changes in envelope compliance would be expected.

The newly collected data was stored by building in an excel worksheet as a separate data source. This data was then combined with the previously collected data to make a complete database for all the 162 commercial buildings. This complete data set has many possible applications. The original idea of providing characterizations of commercial buildings by each different characteristic shown in Table 1 will be enhanced by the additional data in Table 2. The data can also be used to look at details of building subsets such as franchises to identify "cookie cutter" characteristics and assess potential simple and costeffective modifications or retrofits that can be done in the buildings to save energy. 
Table 1. List of Missing Data Collected for Each Building

\begin{tabular}{|c|c|}
\hline Area Traces (exported in csv files) & Roof \\
\hline & Door \\
\hline & Skylight \\
\hline & Exterior Basement Wall \\
\hline Skylight (if present) & Frame type \\
\hline & Pane \\
\hline & Low E? \\
\hline & Glazing \\
\hline & U-Factor \\
\hline & SHGC \\
\hline Exterior Wall (if framed) & Frame type \\
\hline & $16 "$ or $24 "$ o.c. \\
\hline Exterior wall (if concrete block) & Thickness \\
\hline & Grout type \\
\hline & Cells \\
\hline & Density \\
\hline & Furring \\
\hline Exterior Door (if metal) & Insulation \\
\hline & U-Factor \\
\hline Basement wall if solid concrete & Thickness \\
\hline & Furring \\
\hline & Density \\
\hline Basement wall if concrete block & Thickness \\
\hline & Grouted \\
\hline & Cells \\
\hline & Density \\
\hline & Furring \\
\hline Basement Wall general info & Total Wall Height \\
\hline & Depth Below Grade \\
\hline & Cav/Cont Insulation $R$ \\
\hline & Values \\
\hline Floor if slab-on grade & Insulation specifics \\
\hline & Dimension of Insulation \\
\hline
\end{tabular}

Crawlspace Framing (if present)

$\begin{array}{ll}\text { Mechanical Data } & \text { Type } \\ \text { Chiller } & \text { LCWT } \\ \text { Chiller water temp } & \text { ECWT } \\ & \text { CFR } \\ \text { Multiple zone details } & \text { Distribution Type } \\ & \text { Terminal Unit Type } \\ & \text { Reheat type } \\ \text { Condenser Type } & \text { Condenser type } \\ \text { Boiler } & \text { System }\end{array}$


Table 2. Data Previously Collected for Each Building

\begin{tabular}{|l|}
\hline DodgeNumber \\
\hline State \\
\hline City \\
\hline Building Type \\
\hline SummedSize \\
\hline Building Description \\
\hline \multicolumn{1}{|c|}{ ROOF } \\
\hline Primary Roof Structure Type \\
\hline Primary Gross Roof Area \\
\hline Gross Roof Area/Summed Size \\
\hline Primary Roof Cavity-R Value \\
\hline Primary Roof Continuous-R Value \\
\hline Secondary Roof Structure Type \\
\hline Secondary Roof Area \\
\hline Seconday Roof Cavity-R Value \\
\hline Secondary Roof Cont-R Value \\
\hline \\
\hline Primary Wall Type \\
\hline Primary Wall Furring Type \\
\hline Primary Wall Heat Capacity \\
\hline Primary Wall Concrete Thickness \\
\hline Primary Wall Concrete Density \\
\hline Primary Wall Concrete Masonry Unit \\
(CMU) Type \\
\hline PrimaryGrossWallArea \\
\hline Primary Wall Cavity-R Value \\
\hline Primary Wall Continuous-R Value \\
\hline Secondary Wall Type \\
\hline Secondary Wall Furring Type \\
\hline Secondary Wall Heat Capacity \\
\hline Secondary Wall Concrete Thickness \\
\hline Secondary Wall Concrete Density \\
\hline Secondary Wall CMU Type \\
\hline Secondary Gross Wall Area \\
\hline Secondary Wall Cavity-R Value \\
\hline Secondary Wall Continuous-R Value \\
\hline
\end{tabular}

WINDOW

Primary Window Frame Type

Number of Panes

Low-E

Solar Coatings

Operable?

Total Window Gross Area

Window U

Window SHGC

Window Projection Factor

Total Window Wall Ratio

DOOR

Door Type

Swinging Door Gross Area

Rollup Door Gross Area

FLOOR

Primary Floor Type

Primary Gross Floor Area

Primary Slab Perimeter

Primary Floor Cavity- $R$

Primary Floor Cont-R

Primary Perimeter Slab-R

Secondary Floor Type

Secondary Gross Floor Area

Secondary Slab Perimeter

Secondary Floor Cavity-R

Secondary Floor Cont-R

Secondary Perimeter Slab-R

Stories Below Ground

Primary Below Grade Wall-R

Basement Cavity-R

Basement Cont-R

Basement Gross Area
HVAC SYSTEM

Primary Heat Equip Type

Primary Heat Dist Type

Primary Cool Equip Type

Primary Heat Pump Type

Primary Cool Dist Type

Primary VAV box? (True/False)

Primary Condenser Type

Primary Zoning Type

Primary Heat Fuel

Primary Total Heat Btu

Primary Cool Fuel

Primary Total Cool Btu

Total Fan Static Pressure (TSP)

Exterior Fan Static Pressure (ESP)

Secondary Heat Equip Type

Secondary Heat Dist Type

Secondary Cool Equip Type

Secondary Heat Pump Type

Secondary Cool Dist Type

Secondary VAV box? (True/False)

Secondary Condenser Type

Secondary Zoning Type

Secondary Heat Fuel

Secondary Total Heat Btu

Secondary Cooling Fuel

Secondary Total Cool Btu

\section{WATER HEATING}

Primary Equip Type

Primary Equip Fuel

Number of Primary Units

Primary Total GPH/GPM

Primary Total Capacity (Btu)

Secondary Equip Type

Secondary Equip Fuel

Number of Secondary Units

Secondary Total GPM/GPH

Secondary Total Capacity (Btu) 


\section{Materials and Methods}

All of the data was collected from the 162 commercial buildings using the Dodge View software (F.W. Dodge 2002). This program allows the user to look at the construction plans of a building and to zoom in and out of the small print that makes up the plan to find the specific information that is of interest. Each building has its own unique plans and each piece of data that was collected had to be found by looking through these. The list of data previously collected and the list of data collected by us for the COM check $^{\mathrm{TM}}$ runs are in Tables 1 and 2 (U.S. DOE 2003).

Out of the missing data list, the roof size, exterior door area, basement wall and skylight areas were collected using a function of Dodge View called tracing (F.W. Dodge 2002). The trace function relies on the setting of the scale of the drawing which is selected based on the plans themselves (usually $1 / 8$ in. $=1$ $\mathrm{ft}$ ). To trace, the area that is needed is outlined as precise as possible and automatically filled in by the program to calculate the square footage. After this is done, an excel (.csv) output file is exported and the (.tko) trace takeoff file saved for future compilation.

For each category of needed data, different sets of plans provided the information. For example, all of the heating and cooling related information in most buildings was found on the mechanical plans and all of the footing, wall and insulation information were found on the architectural and structural drawings.

In a typical commercial building, out of the 162 dataset, the roof area, door area, and any other traces would be done first. Within the architectural section of the plans the elevation drawings of the building were used for the exterior door traces and the roof plan used for the roof area and skylight area traces if present. All of the exterior wall characteristics such as insulation value and wall construction materials were found on architectural detail drawings and recorded as well. All the data not exported (everything but the area traces) was placed in an excel worksheet with the identifying building number and all required inputs labeled in the first column. Data was not available for each input for each building from the plans, but all reasonable efforts were made to locate each piece of information for each building.

While looking for the missing data in the plans some errors in the previous data collection effort were identified and recorded. These were later fixed in the complete database that was being formed. Because the missing data collection process dealt only with architectural, structural, and mechanical drawings, no changes were identified or made to the electrical (lighting) portions of the dataset.

After all the missing data was collected, the excel worksheet was then properly coded by other PNNL staff and students so that it could be run through the COMcheck ${ }^{\mathrm{TM}}$ program (U.S. DOE 2003). The COMcheck ${ }^{\mathrm{TM}}$ runs would provide the envelope and lighting percentage compliance with ASHRAE/IESNA Standard 90.1-1999 (U.S. DOE 2003). 


\section{Results}

The results of this analysis include only 97 of the total set of 162 commercial buildings. The remaining 65 buildings could not be processed through COMcheck $k^{\mathrm{TM}}$ because major or critical pieces of data were not available on the plans despite the initial and second efforts to find them. This lack of data varied for the 65 buildings but was generally either missing or incomplete square footage data or missing critical insulation levels. Tables 1 and 2 show the missing data that was collected, and the data that was initially collected for the 97 buildings in the final sample. Figures 2 and 3 display the results of the change in percentage compliance of envelope data before and after the missing data was collected.



Figure 2. Distribution of Difference in Compliance between Defaults and Complete Data

Figure 2 displays the change in percentage compliance between COMcheck ${ }^{\mathrm{TM}}$ runs with defaults and COMcheck ${ }^{\mathrm{TM}}$ runs with complete data that was collected for each building (U.S. DOE 2003). A wide range of differences can be seen from -99 percent to many buildings with no change at all. In Figures 2-4 a negative change indicates that compliance was improved. Ignoring the single -99 percent change outlier, the average improvement in the 52 buildings out of the total 97 that complied better was $9.6 \%$ with the use of complete data in place of the defaults. No change at all was seen in 12 of the buildings. The remaining 33 buildings showed a $2.8 \%$ decrease in compliance after the complete data was used. . It is also noted that in 78 of the 97 buildings there was less than a $10 \%$ change in compliance either way. 


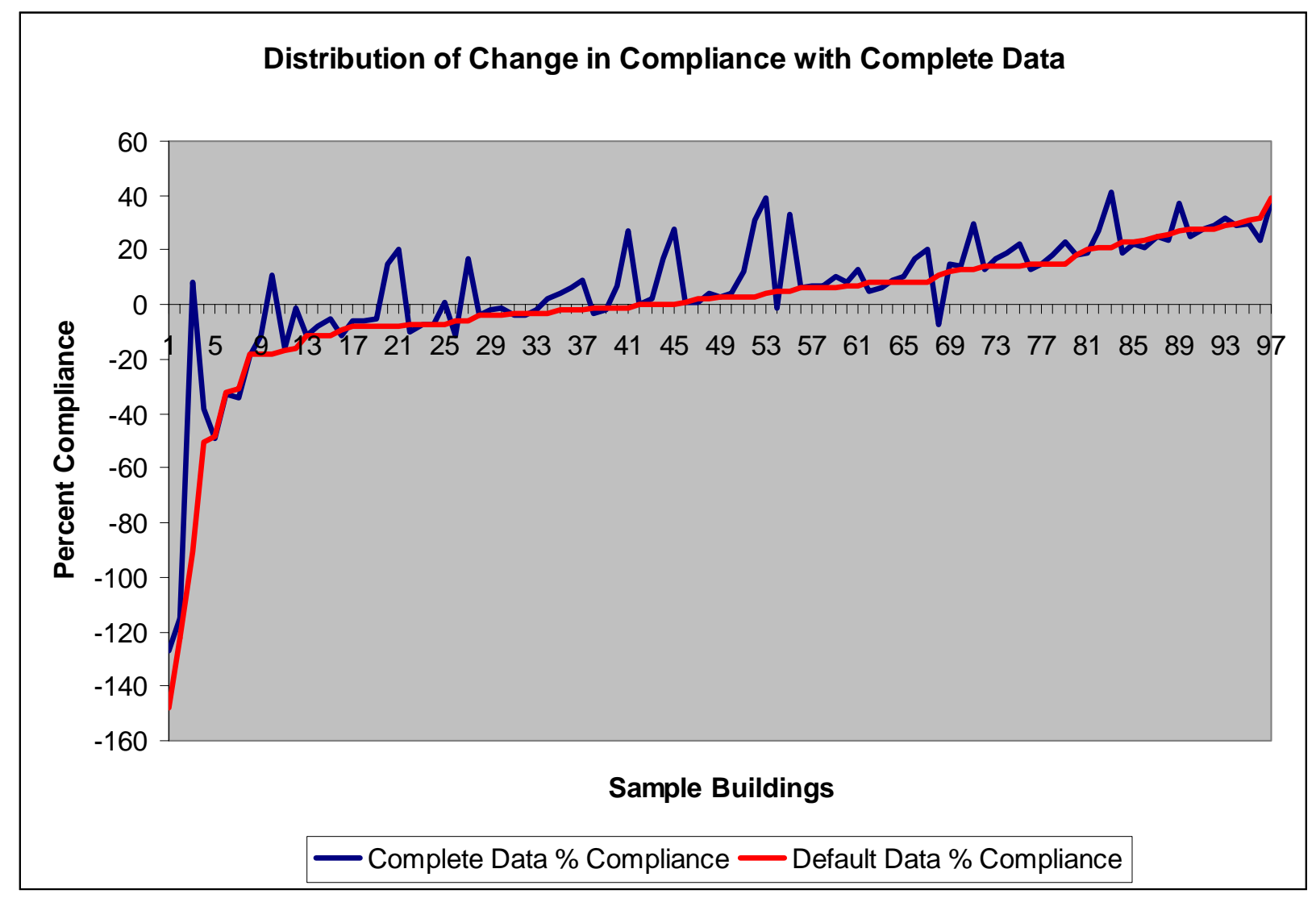

Figure 3. Change as a Result of Complete Data

Figure 3 presents the percentage compliance to ASHRAE/IESNA Standard 90.1-1999 for both default and complete data runs of the buildings through the software. The red line represents the runs using defaults and sorted by compliance percentage. The blue line indicates the change for the better or worse when complete data was used for compliance.

Figure 4 summarizes the lighting percentage compliance of the 112 buildings in the original dataset of 162 buildings that had complete lighting information available. $53.6 \%$ of these buildings met or surpassed the lighting requirements set forth by ASHRAE/IESNA Standard 90.1-1999. 


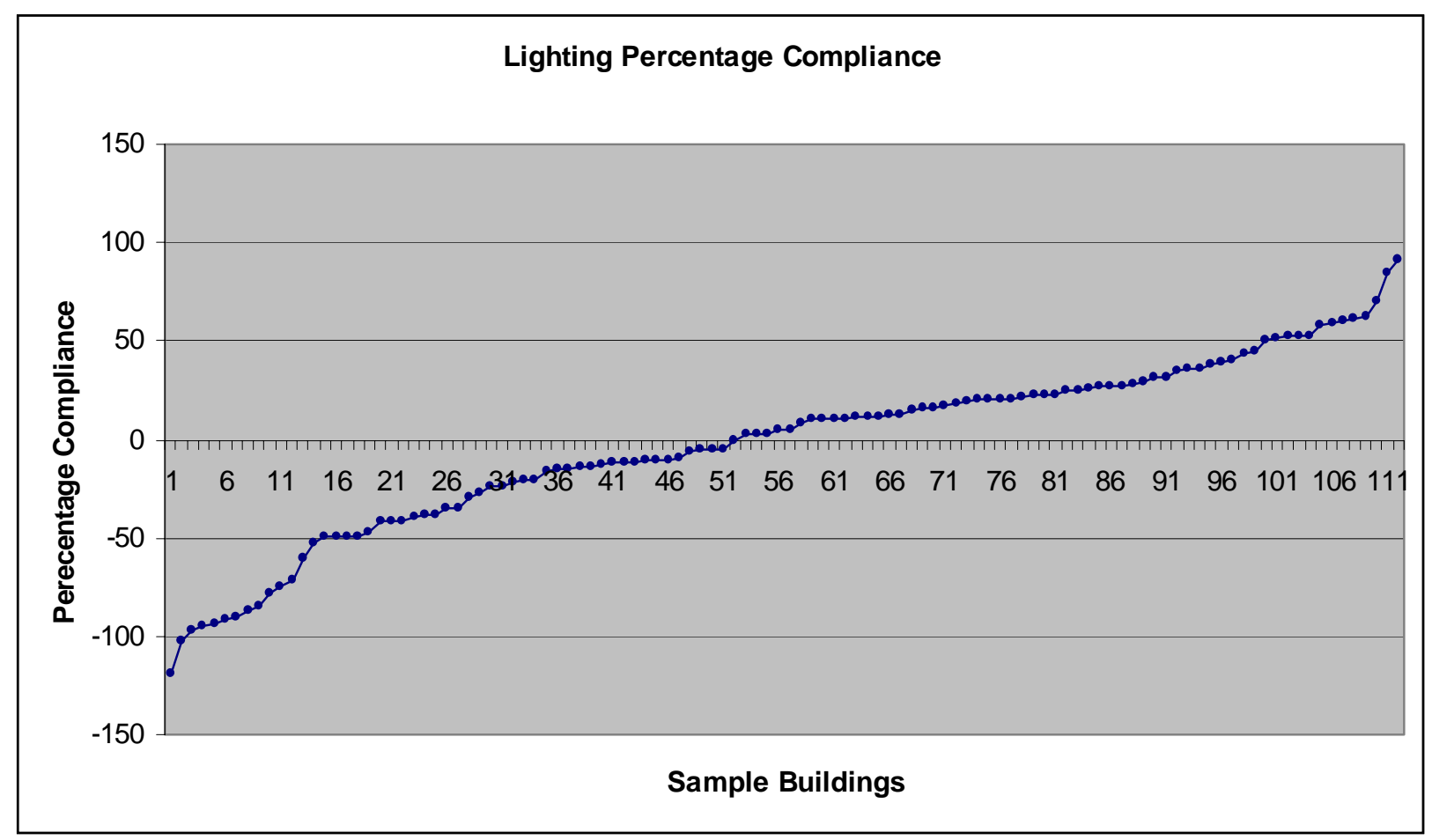

Figure 4. Lighting Percentage Compliance 


\section{Discussion and Conclusion}

What started as a set of 162 commercial buildings slowly turned into a set of 97 for envelope data analysis. To provide accurate results, 65 of the buildings had to be omitted because of essential data that could not be located in the plans or data that was incorrect. The most common of the problems in these included missing exterior wall area and insulation levels.

Many conclusions can be made from the results displayed in Figures 2 and 3. In $20.6 \%$ of the buildings, the missed data made over a $10 \%$ difference in the percentage compliance. This could be attributed to many possible factors. However, it is most likely because the defaults were generally conservative. Many of the defaults are provided by the COMcheck ${ }^{\mathrm{TM}}$ software and others were developed to capture perceived typical values. The defaults in the software are known to be conservative as they generally represent the least efficient value or product for a given item. This effect is the reason that most of the buildings increased their percentage compliance after the complete data was used. These results shown in Figures 2 and 3 support using complete data to improve the accuracy of documented compliance with ASHRAE/IESNA Standard 90.1-1999.

The results for this project also indicate that for a large set of buildings the missing data may not have a large effect in changing average percent compliance. However, for surveying single buildings, all of the data is important and the use of defaults can reduce compliance.

The possibility for missing building data is very evident because the initial set of buildings was cut to less than one-third of its original quantity. However, this also shows that there were extensive efforts to make sure all the data that was used in the analysis was complete and correct. This data set is the first of its kind in that it gives a good stepping stone for understanding how commercial buildings are currently constructed regarding energy features. This project shows one of the many ways in which this dataset can and will be applied. 


\section{Acknowledgements}

This work was performed during my assignment within the Science Undergraduate Laboratory Internship (SULI) program at Pacific Northwest National Laboratory. I thank the U. S. Department of Energy for this wonderful opportunity of participating in the program. My appreciation for this program wouldn't have been possible had it not been for my mentor Eric Richman. I thank you for taking the chance of picking me as your student intern and also thank you for all of the support, knowledge and guidance you provided throughout my internship. I also thank Justin Williams, Suzanne Gaines and Krishnan Gowri for all of their work and help in completing the COMcheck ${ }^{\mathrm{TM}}$ runs (U.S. DOE 2003). 


\section{References}

ANSI/ASHRAE/IESNA. 1999. "Energy Standard for Buildings Except Low-Rise Residential Buildings", Standard 90.1-1999.

F.W. Dodge. 2002. Dodge Plans Via The Internet. [Online] Available:

http://dodge.construction.com/Plans/Electronic/ViaInternet.asp

Swenson, A. 1998. Overview of Commercial Buildings Energy Consumption and Expenditures 1995. [Online] Retrieved September 1, 2003, Available:

http://www.eia.doe.gov/emeu/cbecs/c\&e_rept.html

U.S. Department of Energy. 2003. Commercial Compliance using COMcheck ${ }^{\mathrm{TM}}$. [Online] Available: http://www.energycodes.gov/comcheck/ 